\title{
Analysis of Rice Polisher Machine to Control the Rice Feed Fill Percentage
}

\author{
Mr.R.Narasimhan ${ }^{\# 1}$, Dr. K.R.Vijayakumar ${ }^{* 2}$ \\ ${ }^{\#}$ Mechanical Department, Research scholar, ${ }^{*}$ Mechanical Department, Professor. \\ ${ }^{1}$ St.Peter's Institute of Higher Educational and Research University Avadi, Chennai. \\ ${ }^{2}$ Dr MGR Educational Research Institute University, Maduravoyal, Chennai. \\ 1narasima123@gmail.com \\ ${ }^{2} 1$ sjv2002@gmail.com
}

\begin{abstract}
The aim of this study is to develop an understanding of the analysis of rice polisher feed fill percentage to be controlled and to reduce the wear of rice polisher machine wear parts. By this wear causes the rice quality and quantity was get more damaged. There is high production loss this process we reported the result in detailed wear and feed fill analysis to be controlled. The processes determine that what improvement can be done in design part to control the feed fill percentage and to reduce the wear.
\end{abstract}

Keyword - Cams, Milling, Polishers, wear, Feed Fill.

\section{INTRODUCTION}

The rice is a seed which form as grass species. The most consumed staple food for the very large part of human population is Asia [1-3]. Rice is the agricultural commodity in worldwide highest production [5]. In this modern world there are various production methods has been adopted to cultivate and process the grain. Rice milling technologies process is one of most advanced process. This involved in to milling the rice process. In this paper we present about the finding and what we observed in rice polisher machine of different makes. The finding which helps design modification of feed screw and control of feed fill.

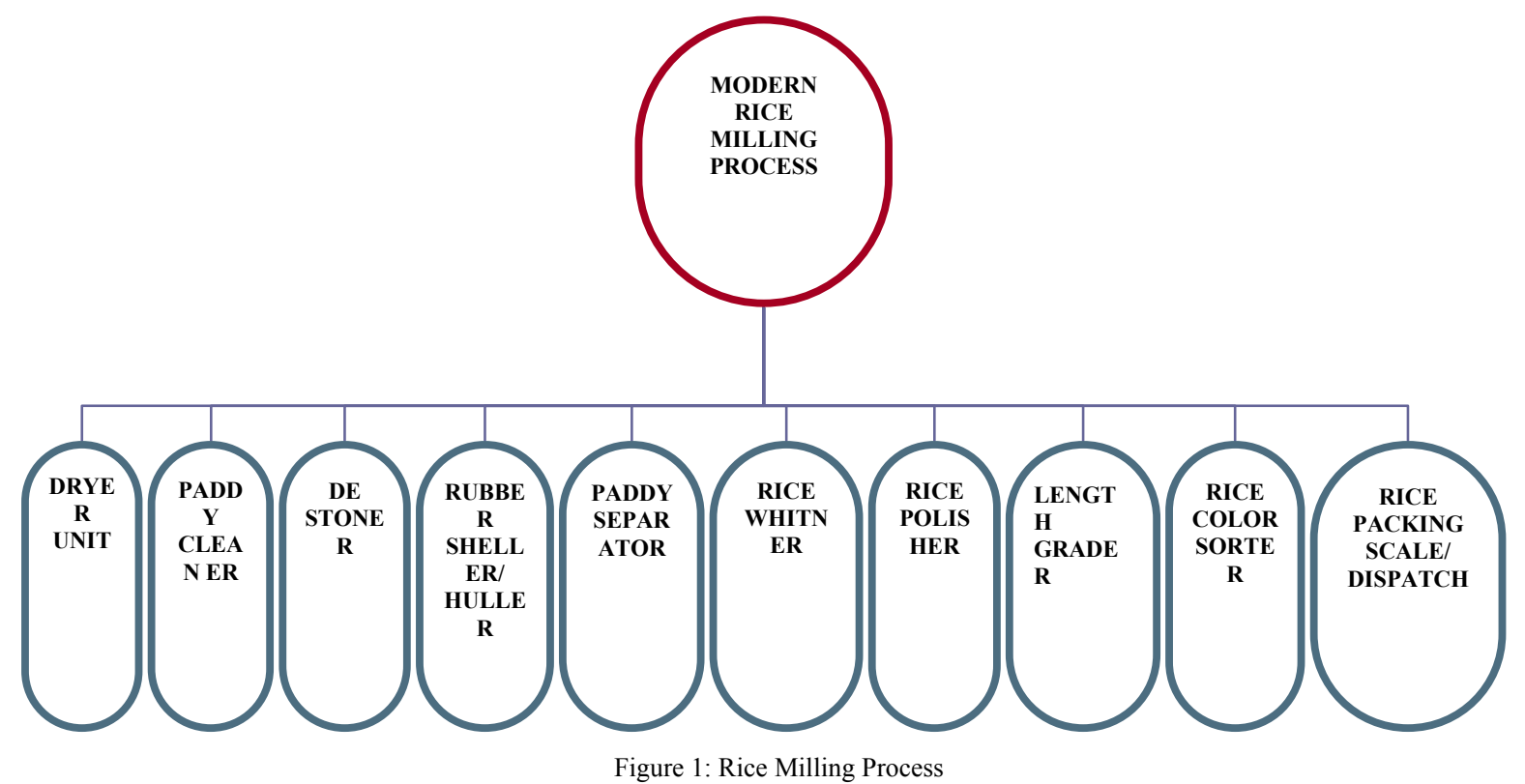

II. RICE POLISHER MACHINE

The rice polishing is a major process in modern rice milling to remove the bran dust from the rice grain. In this process polishing machine parts gets worn out by more feed fill to be controlled. The feed fill should be modified based on change in input rice level and output rice level. Design modification also carried out to control the levels.

\section{FLOW ANALYSIS OF RICE POLISHER}

The flow of moisturized rice in the polishing chamber of rice polisher's had been carried out. The polishing chamber is fed with wet rice by the feed screw running at a rated rpm, and usually two start feed screw, lead of $120 \mathrm{~mm}$ is used, thread form of trapezoid or rectangle [2]. Two cams roughing and finishing cams in the sieve polishing chamber rotate at the same speed of the feed screw. The roughing cam mounted, immediately after the feed screw has either triple taper or single taper to receive the wet rice fed by the screw and push radically outward over the inner surface of sieve chamber for rough polishing [3]. The rice gets rough polishing and flows 
over the second stage straight finishing cam at a rate of flow depending on the flow restrictions inside the polishing chamber that is the minimum gap between diameter maximum of the roughing cam and the inner diameter of sieve chamber [8]. This cam design results in varying feed fill rate, $\mathrm{X}$, of the rice polisher.

The cams have to be designed depending on the polishing capacity of rice polisher for optimal performance with desired polishing level and wear life of cam as per the fill rate graph.

\section{A.FEED FILL PERCENTAGE PROCESS}

The pressure acting on the polisher chamber wall is a function of several factors, including bulk density of the rice grains and their velocity [9]. Bulk density determines the packing of the particles which, in turn allows calculation of the degree of freedom of the rice grains to accelerate and impact on the Sieve. The flow rate of the grains through the machine can be measured using flow velocity as shown in Figure 2.

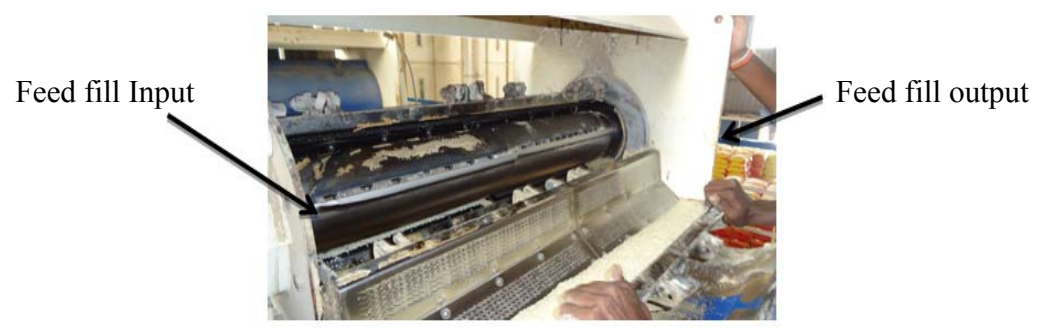

Figure 2: Feed Fill

TABLE I. FROM VARIOUS MAKES FEED FILL PERCENTAGE WAS CALCULATED AND TABULATED BELOW

\begin{tabular}{|l|l|l|l|l|l|}
\hline \multicolumn{7}{|c|}{ Feed Fill Percentage Data } \\
\hline $\begin{array}{c}\text { SL } \\
\text { NO }\end{array}$ & $\begin{array}{c}\text { MAKE (3 TO 8 } \\
\text { TON / Hr ) }\end{array}$ & $\begin{array}{c}\text { Input Filling } \\
\text { rate in kg/min }\end{array}$ & $\begin{array}{c}\text { Polishing timing } \\
\text { in minutes }\end{array}$ & $\begin{array}{c}\text { Polished rice } \\
\text { output in kg }\end{array}$ & $\begin{array}{c}\text { FEED } \\
\text { FILL \% }\end{array}$ \\
\hline 1 & Machine Sample 1 & $39 \mathrm{~kg}$ & 1 Minutes & $35 \mathrm{~kg}$ & $19 \%$ \\
\hline 2 & Machine Sample 2 & $35 \mathrm{~kg}$ & 1 Minutes & $32 \mathrm{~kg}$ & $18.5 \%$ \\
\hline 3 & Machine Sample 3 & $33 \mathrm{~kg}$ & 1 Minutes & $30 \mathrm{~kg}$ & $18 \%$ \\
\hline 4 & Machine Sample 4 & $62 \mathrm{~kg}$ & 1 Minutes & $60 \mathrm{~kg}$ & $22 \%$ \\
\hline 5 & Machine Sample 5 & $63 \mathrm{~kg}$ & 1 Minutes & $61 \mathrm{~kg}$ & $22 \%$ \\
\hline 6 & Machine Sample 6 & $35 \mathrm{~kg}$ & 1 Minutes & $33 \mathrm{~kg}$ & $20 \%$ \\
\hline
\end{tabular}

Note: FEED FILL PERCENTAGE DATA TAKE FROM RICE MILL SITE

\section{Feed Fill Percentage Data}

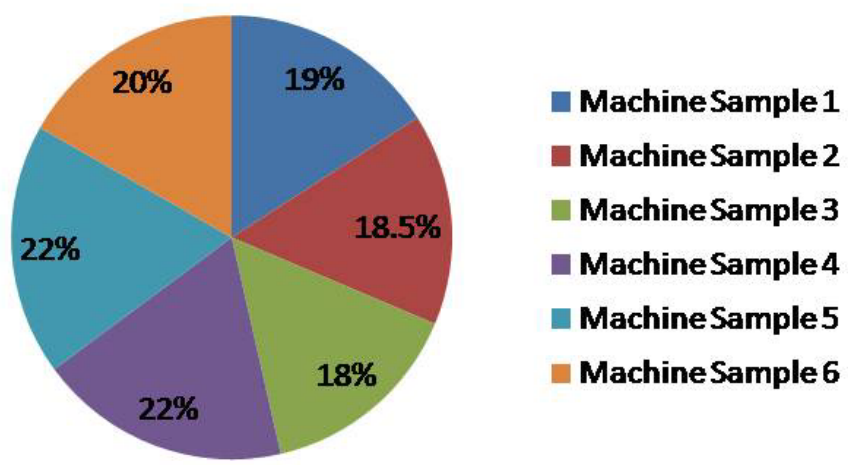

Figure 3: Feed fill percentage

B. Feed Screw Velocity

A bulk density of rice grains can be assumed in order to determine the degree of fill for different flow rates. 


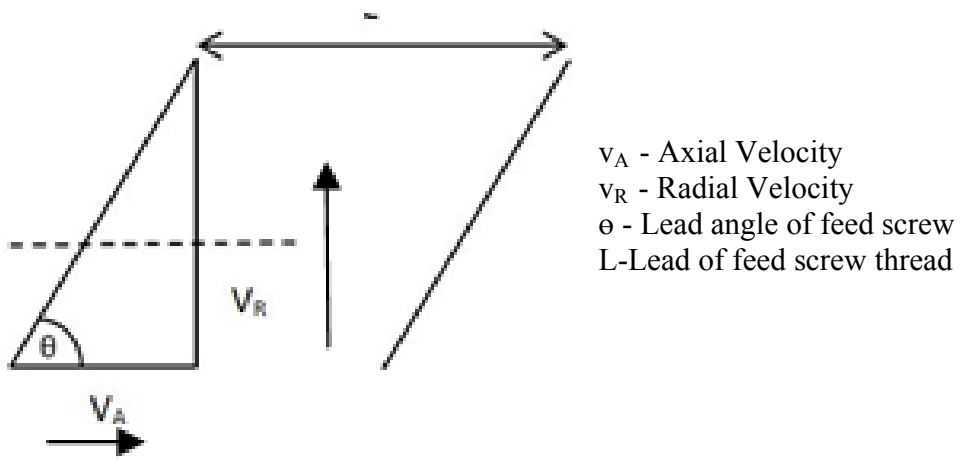

Figure 4: Feed Screw Velocity diagram

The lead of feed screw thread is $180 \mathrm{~mm}$ and the axial flow velocity is known, which allows the calculation of the radial velocity of the screw thread (VR). This allows the simple calculation of the number of thread passes per hour. When considering processing rate in $\mathrm{kg} / \mathrm{hr}$ of grains and bulk density, the feed fill can be determined, Figure 4.

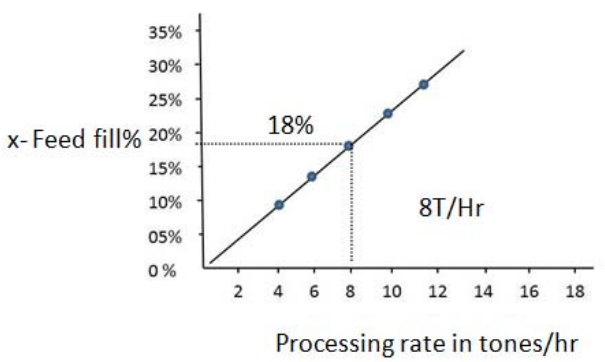

$\rho \mathrm{v}_{\mathrm{v}} \times \mathrm{n}=\mathrm{m}$

$\rho$ - Bulk density of grains

$\mathrm{v}_{\mathrm{v}}-$ Feed Volume $\mathrm{m}^{3}$

$\mathrm{x}$ - Feed Fill \%

$\mathrm{n}$ - Number of thread fill (start)/min

$\mathrm{m}$ - Processing rate in $\mathrm{kg} / \mathrm{min}$

Figure 5: Feed screw fills percentage Vs processing rate

The result is interesting, as it shows that the inlet is generally operating at around an $18 \%$ fill corresponding machine. The operators believed that it has to be much higher (by intuition) since the flow appears to be impeded when operating at high feed rates leading to the conclusion that this resistance is not due to the feed chamber being full. It would also be useful to determine the percentage fill for the main chamber; however, the calculation relies on knowing the axial velocity of the grains inside the polishing chamber.

The velocity of grains over the feed screw is only known. As the feed screw feeds the rice into the chamber, the fill percentage can help to indicate conditions at the main chamber inlet, but doesn't provide any means of determining pressure in the polisher chamber.

Cams are designed to handle rice polishing at specified rate, $8 \mathrm{~T} / \mathrm{Hr}$

Hence, Maximum capacity $=8000 \mathrm{Kgf} /$ hour.

Bulk density of grains $=757 \mathrm{kgf} / \mathrm{m}^{3}$

Hence, Output flow rate at full capacity $\quad=$ Maximum Capacity / Bulk density of grains

$=8,000 / 757$

$=10.57 \mathrm{~m}^{3} / \mathrm{hr}$

Output flow rate of polished grains $/ \mathrm{min}=$ Output flow rate at maximum capacity $/ 60$, Figure 4.

$$
\begin{aligned}
& =10.57 / 60 \\
& =0.176 \mathrm{~m}^{3} / \mathrm{min}
\end{aligned}
$$



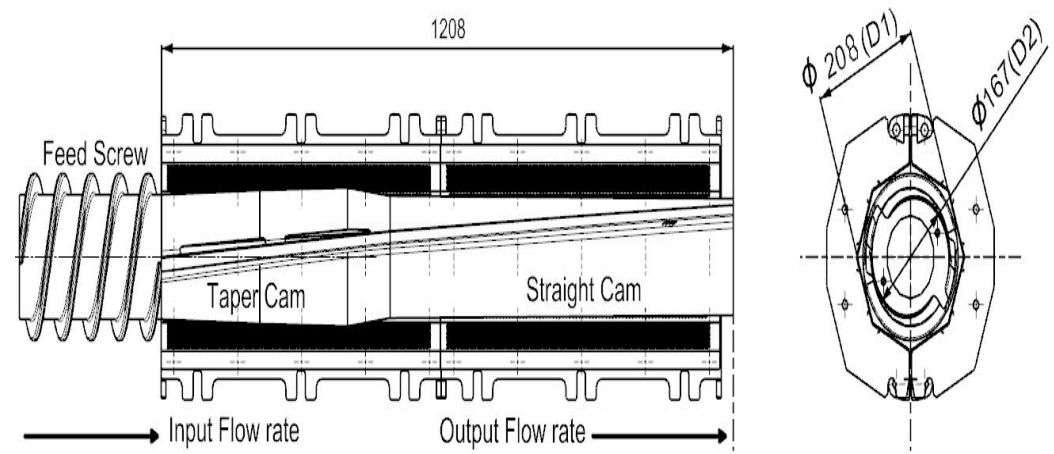

Figure 6: Feed screw, Cams inside Polishing Chamber and flow gap

$\mathrm{V}_{\mathrm{f}}=$ Flow velocity in polishing

$\left[\Pi\left(D_{1}{ }^{2}-D_{2}{ }^{2}\right) \times V_{f}\right] / 4=$ Output flow rate of polished grains

$\mathrm{V}_{\mathrm{f}}=$ Output flow rate of polished grains $\mathrm{x} 4 /\left[\Pi\left(\mathrm{D}_{1}{ }^{2}-\mathrm{D}_{2}{ }^{2}\right)\right]$

$\mathrm{V}_{\mathrm{f}}=0.176 \times 4 /\left[\Pi(0.208)^{2}-(0.167)^{2}\right]=14.97 \mathrm{~m} / \mathrm{min}$

\section{Input flow $=(2 \times h \times b \times L \times N) / \sin \alpha$}

Where,

$\mathrm{h}=$ height of the teeth, $\mathrm{m}$

$\mathrm{b}=$ breath of the teeth, $\mathrm{m}$

$\mathrm{L}=$ Length of the teeth, $\mathrm{m}$

$\mathrm{N}=$ Speed in, rpm

Input flow rate of polished grains $=(2 \times 0.025 \times 0.08 \times 0.18 \times 1 \times 600) / \sin \alpha$

Input flow rate for feed screw (Two start, $180 \mathrm{~mm}$ lead, and pitch $90 \mathrm{~mm}$ ), $=1.44 \mathrm{~m}^{3} / \mathrm{min}$.

$\%$ Feed fill $\quad=($ Output flow rate of polished rice $/$ Input flow rate of rice grains $) \times 100$

$$
\begin{aligned}
& =(0.176 / 1.44) \times 100 \\
& =\mathbf{1 2 . 2} \%
\end{aligned}
$$

This is a low feed fill percentage which results in excessive pressure on polishing Cam. This condition leads to excessive wear of the Cams, especially on the first stage Cam.

\section{For feed screw with lead of 120 mm, Figure 6}

Input flow rate of polished grains $=(2 \times 0.025 \times 0.05 \times 0.12 \times 1 \times 600) / \sin \alpha=0.844 \mathrm{~m}^{3} / \mathrm{min}$

$\%$ Feed fill $=($ Output flow rate of polished rice $/$ Input flow rate of rice grains $) \times 100$

$$
\begin{aligned}
& =(0.176 / 0.844) \times 100 \\
& =\mathbf{2 0 . 8} \%
\end{aligned}
$$

\section{CONCLUSION}

If the feed fill rate is lower than the recommended value the wear rate of cam is higher. The feed fill rate for the rated output is lower, when the restriction for the flow of rice is high in which is a function of the diametrical gap at the section of maximum diameter of the cam with the sieve inner. This percentage of feed fill, $20.80 \%$ To $23 \%$ is closer to the feed fill percentage $18 \%$ as seen in the graph. Higher percentage of fill rate reduces Cam wear rate but it also results in reducing pressure inside the polishing chamber. The rice polishing is smother in this operation.

\section{REFERENCES}

[1] Debabandya Mohapatra; Satish Bal (2004). Wear of Rice in an Abrasive Milling Operation, Part 1: Prediction of Degree of Milling. article.Journal of Biosystems Engineering, 88 (3), 337-342,

[2] Debabandya Mohapatra; Satish Bal (2004). Wear of Rice in an Abrasive Milling Operation, Part II: Prediction of Bulk Temperature Rise. article.Journal of Biosystems Engineering, 89 (1), 101-108

[3] Kshirod_R._Bhattacharya "Milling quality of rice";Rice quality; Woodhead Publishing Limited (2011), (pp 61-99).

[4] Saeed Firouzi, Mohammad Reza Alizadeh; "An investigation of the effects of harvesting time and milling moisture content of paddy on the quality of milled rice"; International Journal of Biosciences (2013); Vol. 3, No. 10, p. 133- 138,

[5] Saeed Firouzi and Mohammad Reza Alizadeh; "Effect of Whitener Type and Paddy Moisture Content on Rice Grain Damage During Milling Process" American-Eurasian J. Agric. \& Environ. Sci. (2011), vol. - 10 (3): 470-474,

[6] Sayed Hossein Payman, Iraj Bagheri, Hemad Zareiforoush; "Milling characteristics of rice grains as affected by paddy mixture ratio and moisture content”; International Journal of Biosciences (2014); Vol. 4, No. 2, p. 87-97, 
[7] R.H. Dilday; "Influence of Thresher Cylinder Speed and Grainmoisture at Harvest on Millingyieldof Rice"; Proceedings Arkansas Academy of Science (1987), Vol.41.

[8] Milling quality of rice, Rice Quality - A Guide to Rice Properties and Analysis , 2011, Pages 61-99

AUTHOR PROFILE

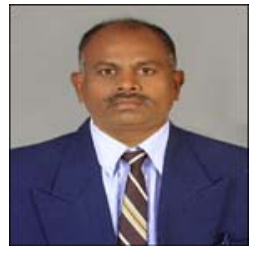

Dr. K.R.Vijayakumar is working as a professor in the department of Mechanical Engineering, Dr MGR Educational Research Institute University, Maduravoyal, Chennai, India. He obtained his B.E (Mechanical Engineering) degree from Bharathiar University, Coimbatore, India, in 1993, M.E (Engineering Design) degree from Anna University, Chennai \& PhD from Anna University. His current research interest includes Composite Materials, Engineering Design and CAD. He is a Life Member of the Indian Society for Technical Education.

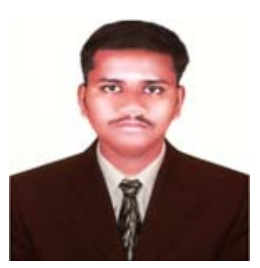

R.Narasimhan is a Research scholar of the Department of Mechanical Engineering, St.Peter's Institute of Higher Educational and Research University Avadi, Chennai. He obtained his Diploma in Mechanical Engineering from AMK Technological Polytechnic College Chennai in 2008, B.tech (Mechanical Engineering) degree from Dr. M.G.R. University, Chennai, in 2011\& M.tech (Design Engineering) degree from Dr. M.G.R. University, Chennai, in 2013, Chennai. His current research interest includes Post harvesting process, Composite Materials, Engineering Design and CAD. 